\title{
Communications
}

\section{Automation and the Service Attitudes of ARL Circulation Managers}

James R. MARTIN: University of Rochester Library, Rochester, New York.

The circulation function in our large academic libraries has undergone two important transformations since the turn of the century. The first of these is departmentalization; the second, automation. The departmentalization of the circulation function has tended to separate the circulation department from the library's educational and information functions, the more "professional" aspects of librarianship. Laurence Miller makes this point in his dissertation, "Changing Patterns of Circulation Services in University Libraries," which focuses on the rise of circulation departmentalization. ${ }^{1}$ Miller surveyed large academic libraries to determine if certain services-reference, interlibrary loan, orientation, catalog assistance-were being withdrawn from the circulation function. After verifying a withdrawal of these services and identifying them as the "professional" ones, Miller drew the conclusion that circulation is therefore suspect as a professional activity. ${ }^{2} \mathrm{His}$ are generally held conclusions as Robert Oram suggests:

Until recently, librarians have been reluctant to deal with circulation problems on an organized basis. The belief that circulation was, in part at least, custodial and clerical rather than managerial and professional underlies much of the reluctance to solve mutual circulation problems through a professional group. $^{3}$

Paralleling this change in the circulation function's organizational setting, the mechanization of the circulation process has continued to move from the laborious and slow use of manual procedures and book cards toward the immediate updating and record keeping of the online system. Circulation automation has passed from the early days of simply mechanizing files (represented by the batch system) to the present, where libraries have the potential capacity to perform the complete circulation control process with real-time systems. ${ }^{4}$ Sophisticated online systems have begun to truly control the complete circulation function.

The metamorphosis of circulation automation-from simple mechanization to full computerization-has had a tremendous impact on the technical side, the processes, of the circulation department. Likewise it may well have had impact on the service attitudes, priorities, and leadership of the department. The level of automation may relate to the circulation manager's attitudes and priorities, and in the words of an American Library Association committee, "the impact of automation might change the image of the circulation librarian." ${ }^{5}$ As it automates, gaining control over its own processes, the circulation department and its manager may actually become more responsive to its users-more service oriented, more "professional."

In February 1980, a questionnaire was sent to circulation managers of all the ninety-eight academic libraries that hold membership in the Association of Research Libraries. ${ }^{6}$ It sought to (1) identify the degree and state of automation of the circulation function, classified by the three system categories of manual, batch, and online systems, and (2) to capture opinions on the circulation manager's view of his management role and his attitudes on service issues and user demands. These attitudes were related to the three types of systems. Seventy-six questionnaires were returned, for a 78 percent response rate. 


\section{CIRCULATION DEPARTMENT CHARACTERISTICS}

Circulation departments ranged in size from 4 to 78 FTE employees. The average department size was 18, the median 14.25. The number of students employed ranged from 0 to 175. Twenty-nine percent of managers said staffing was not adequate and 45 percent said they had to depend too heavily upon students. Fifty-seven percent of managers of manual systems responded that they had to depend too heavily upon students, versus 27 percent of batch and 50 percent of online managers. (Because of variations in what is counted, transaction volume figures are not particularly informative.)

\section{CIRCULATION SYSTEM CHARACTERISTICS}

The seventy-six responding libraries reported approximately thirty-two different system configurations. Thirty-nine percent of these systems were manual, 34 percent were batch, and 26 percent were online. Nineteen percent of the total were manual McBee systems and 15 percent were LIBS100 online systems. Manual systems had been in use an average of twenty-six years, batch systems an average of eight years (range: ten months to eighteen years), and online systems an average of three years (range: three months to eight years).

\section{CIRCULATION MANAGER CHARACTERISTICS}

Typically, the circulation manager in an ARL library is the head of a department. ARL circulation managers had held their positions from six months to twenty years. Five years was the average, but 68 percent listed five years or less. Gender was evenly distributed: thirty-eight males and thirtyeight females. The managers of manual systems were 43 percent male/ 57 percent female, those of batch systems were 54 percent male/ 46 percent female, and of online systems 55 percent male/ 45 percent female. Seventy percent of all managers had an MLS, and 30 percent did not; 40 percent of managers of online systems did not have an MLS. A majority of circulation man- agers (57 percent) reported spending over 25 percent of their time on matters outside of strictly circulation concerns. In fact a substantial minority, 23 percent of all managers, spent over 50 percent on extracirculation matters.

\section{SATISFACTION WITH CIRCULATION SYSTEM}

As a group, ARL circulation managers are not satisfied with their systems, as table 1 shows. Online-system managers consistently rate their systems most highly.

Asked if their systems were "close to ideal," only 17 percent of all respondents were affirmative. Only 3 percent of manual-system managers agreed that their system was "close to ideal"-as compared to 12 percent of batch managers and 45 percent of online managers. Hidden in these averages is the fact that three managers gave their systems perfect scores on all four questions and those systems were all online: GEAC, LIBS100, and an IBM-based online system. (Table 2 summarizes responses on the four system-performance statements.)

\section{HARDWARE, SOFTWARE, AND DOWNTIME}

Circulation managers with automated systems also reported on their experience with equipment, software, and downtime. Batch-system managers were more satisfied with hardware and software ( 74 percent for both) than were online managers (60 percent satisfied with hardware and 65 percent with software). However, open-ended questions revealed that dissatisfaction with online-system hardware and software centered around limitations of the LIBS100 system (used by 55 percent of online-system managers). The LIBS100 system was panned for "inflexible software," "poor fines system," and "lack of reserve book features." (These are all long-recognized limitations that were partially addressed in the relatively recent Release 24 .) The downtime situation was more satisfactory, however, for online managers than batch managers. Seventy-five percent reported downtime was not a problem as against more than 63 percent of batch-system managers. 
Table 1. Responses by Type of System ( $N=30$ Manual, 26 Batch, 20 Online $)$

$\begin{array}{ccc}\text { Strongly } & \text { No } & \\ \text { Agree } & \text { Agree } & \text { Opinion }\end{array}$

Strongly

Disagree

"Our Circulation System Is Completely Adequate"

\begin{tabular}{|c|c|c|c|c|c|}
\hline Manual & $1(3 \%)$ & $4(13 \%)$ & $1(3 \%)$ & $12(40 \%)$ & $14(40 \%)$ \\
\hline Batch & $1(4 \%)$ & $5(19 \%)$ & $1(4 \%)$ & $13(50 \%)$ & $6(23 \%)$ \\
\hline Online & $3(15 \%)$ & $7(35 \%)$ & $1(5 \%)$ & $6(30 \%)$ & $3(15 \%)$ \\
\hline \multicolumn{6}{|c|}{ "Our Circulation System Is Reliable" } \\
\hline Manual & $1(3 \%)$ & $15(50 \%)$ & $1(3 \%)$ & $10(33 \%)$ & $3(10 \%)$ \\
\hline Batch & $3(12 \%)$ & $9(35 \%)$ & - & $11(42 \%)$ & $3(12 \%)$ \\
\hline Online & $5(25 \%)$ & $11(55 \%)$ & - & $3(15 \%)$ & $1(5 \%)$ \\
\hline \multicolumn{6}{|c|}{ "Our Circulation System's Records Are Very Accurate" } \\
\hline Manual & $2(7 \%)$ & $7(23 \%)$ & $2(7 \%)$ & $16(53 \%)$ & $3(10 \%)$ \\
\hline Batch & $3(8 \%)$ & $12(46 \%)$ & - & $9(35 \%)$ & $3(12 \%)$ \\
\hline Online & $4(20 \%)$ & $10(50 \%)$ & - & $6(30 \%)$ & - \\
\hline \multicolumn{6}{|c|}{ "Our Circulation System Is Close to Ideal" } \\
\hline Manual & - & $1(3 \%)$ & - & $7(23 \%)$ & $22(73 \%)$ \\
\hline Batch & - & $3(12 \%)$ & - & $8(31 \%)$ & $13(50 \%)$ \\
\hline Online & $3(15 \%)$ & $6(30 \%)$ & $3(15 \%)$ & $4(20 \%)$ & $4(20 \%)$ \\
\hline
\end{tabular}

Table 2. Summary of Responses on Four System Questions (Detail Given in Table 1)

$\begin{array}{lcccccc} & \text { Mean } & \text { Median } & \begin{array}{c}\text { Standard } \\ \text { Deviation }\end{array} & \begin{array}{c}\text { Minimum } \\ \text { Value }\end{array} & \begin{array}{c}\text { Maximum } \\ \text { Value }\end{array} & \text { Variance } \\ \text { Manual } & 9^{*} & 9 & 3.27 & 4 & 16 & 11 \\ \text { Batch } & 10.08^{*} & 8.5 & 3.81 & 4 & 18 & 15 \\ \text { Online } & 13.45^{*} & 14 & 4.57 & 5 & 20 & 21\end{array}$

${ }^{*} 20=$ strongly agree, $16=$ agree, $12=$ no opinion, $8=$ disagree, $4=$ strongly disagree.

\section{SERVICE ATTITUDES}

Respondents were asked to mark attitude statements on a five-point scale: "strongly agree," "agree," "no opinion," "disagree," and "strongly disagree." Attitude statements fell into four categories: (1) specific service concerns, (2) the importance of the managerial role, (3) user problems, contacts and complaints, and (4) user demands and expectations. The averages of the last three groups were used to explore the question of association between level of automation and manager service attitudes (see table 3).

\section{SPECIFIC SERVICE CONCERNS}

Ninety percent of circulation managers agreed that "speed of service is very important to users," and no online-system manager disagreed. Forty-three percent of manual-system managers agreed that "control of circulating books tends to be inade- quate." This compares to 16 percent of batch managers and 15 percent of onlinesystem managers. Asked whether "users tend to expect more service than the department can give," 56 percent of manual managers agreed, as did 46 percent of batch managers and 40 percent of online-system managers.

\section{ATTITUDES TOWARD MANAGEMENT ROLE}

The study found that circulation managers are uniformly strong in their affirmation of the importance of their role, with a slight tendency for online managers to be more affirmative. In fact, 100 percent of respondents agreed with the statement that the "management of the circulation function is important." Ninety-three percent agreed that "circulation management should rank high among the library's priorities." Ninety-five percent disagreed with the negative statement that "circulation 
Table 3. Attitude Responses, Averages

$$
\begin{gathered}
\text { Management } \\
\text { Role } \\
\text { (9 Questions) }
\end{gathered}
$$

Manual

Batch

Online

\subsection{8}

4.34

4.48
Demands and

Expectations

(6 Questions)

3.48

3.52

3.46
Contacts and

Complaints

(6 Questions)

3.88

3.9

4.03
Totals

3.913

3.92

3.99

$5=$ most positive response.

$1=$ least positive response.

management offers little opportunity for the exercise of initiative." Ninety-four percent of all managers disagreed that "circulation management lacks complexity."

\section{ATTITUDES \\ TOWARD USER PROBLEMS, CONTACTS, AND COMPLAINTS}

The study found that circulation managers are uniformly strong in their desire to respond to user complaints and problems, but with a slight tendency for online managers to be more favorable to the user. One hundred percent of online managers regarded user contacts as pleasant, as did 93 percent of manual and batch managers. Ninety-five percent of online managers, 92 percent of batch managers, and 87 percent of manual managers affirm that patron contact provides the challenge in circulation work. Eighty percent of online managers and 73 percent of manual and batch managers rejected the statement that "complaints tend to be unfounded." Sixty-five percent of the respondents of online systems were more likely to favor the user by thinking "complaints are most often substantive," as compared to 50 percent of manual managers and 48 percent of batch managers. Ninety percent of online managers disagreed that users "complain far too much," compared with 84 percent of batch managers and 79 percent of manual managers.

\section{ATTITUDES TOWARD USER DEMANDS AND EXPECTATIONS}

Circulation managers are generally favorable in their attitudes toward user demands and expectations. Several statements in this area, however, ran contrary to the tendency of online managers to agree slightly more with attitudes favorable to the user than managers of batch and manual systems. For example, while 93 percent of manual-system managers and 85 percent of batch managers agreed that "the circulation department should be oriented towards users' expectations," only 70 percent of online managers did. On the statement, "Users should be more tolerant of limitations in circulation services," manual managers disagreed by 34 percent, batch managers by 40 percent, and online managers by 20 percent.

These responses against the trend of the online manager as more user oriented may be due to the fact that the study was not completely successful in differentiating between responses based on general attitudes and those based directly on the specific system in use. In other words, the relative quality of each circulation system or even the "bugs" peculiar to a specific system may affect one's attitude toward the user's need to tolerate the limitations of that system. Manual-system managers know the limitations on their service are keyed to inefficient systems, whereas online-system managers know their systems and services are already at a high level. This knowledge of the system in use colors service attitudes.

\section{CONCLUSION}

The study found a depressed state of circulation-system development and support in ARL libraries. Seventy-four percent of circulation managers, on average, rated their systems negatively on basic system integrity, as shown in table 2.

The thirty manual-system managers gave their systems an average score of 9 , to the effect that their systems were ideal, adequate, reliable, and accurate. The twentysix batch managers gave their systems an average score of 10.08 , the twenty online managers an average of 13.45 . Recognizing the considerable constraints under which 
today's large academic libraries struggle, there is, nonetheless, room for criticism of library priorities.

This study must be viewed as only a first step (largely tentative and exploratory) in relating automation with service attitudes. It suggests that online systems may be associated with managers more positive in their view of the management role and more positive in their attitudes toward users than batch- and manual-system managers. Further research would be useful at this point to compare levels of automation (manual, batch, and online) with circulation-staff service attitudes or those of patrons using the systems.

\section{REFERENCES}

1. Laurence Miller, "Changing Patterns of Circulation Services in University Libraries" (Ph.D. dissertation, Florida State University, 1971), p.iii.

2. Ibid., p.149.

3. Robert Oram, "Circulation," in Allen Kent and Harold Lancour, eds., Encyclopedia of Library and Information Science, V.5 (New York: Marcel Dekker, 1971), p.1.

4. William H. Scholz, "Computer-Based Circulation Systems-A Current Review and Evaluation," Library Technology Reports 13:237 (May 1977).

5. Robert Oram, "Circulation," p.2.

6. James Robert Martin, "Automation and the Service Environment of the Circulation Manager" (Ph.D. dissertation, Florida State University, 1980), p.22.

\section{Statistics on Headings in the MARC File}

Sally H. McCALLUM and James L. GODWIN: Network Development Office, Library of Congress, Washington, D.C.

In designing an automated system, it is important to understand the characteristics of the data that will reside in the system. Work is under way in the Network Development Office of the Library of Congress (LC) that focuses on the design requirements of a nationwide authority file. In support of this work, statistics relating to headings that appear on the bibliographic records in the LC MARC II files were gathered. These statistics provide information on characteristics of headings and on the expected sizes and growth rates of various subsets of authority files. This information will assist in making decisions concerning the contents of authority files for different types of headings and the frequency of update required for the various file subsets. The National Commission on Libraries and Information Science supported this work.

Use of these statistics to assist in system design is largely system-dependent; however, some general implications are given in the last section of this paper. In general, counts were made of the number of bibliographic records, headings that appear in those records, and distinct headings that appear on the records. The statistics were broken down by year, by type of heading, and by file.

In this paper, distinct headings are those left in a file after removal of duplicates. Distinctness will not be used to imply that a heading appears only once in a source bibliographic file, although distinct headings may in fact have only a single occurrence. Thus, a file of records containing the distinct headings from a set of bibliographic records is equivalent in size to a MARC authority file of the headings in those bibliographic records.

\section{METHODOLOGY}

These statistics were derived from four MARC II bibliographic record files maintained internally at LC: books, serials, maps, and films. The files contain updated versions of all MARC records that have been distributed by LC on the books, serials, maps, and films tapes from 1969 through October 1979, and a few records that were then in the process of distribution. The files do not contain CIP records. A total of 1,336,182 bibliographic records were processed, including 1,134,069 from the books file, 90,174 from the serials file, 60,758 from the maps file, and 51,176 from the films file.

A file of special records, called access point (AP) records, was created that contains one record for the contents of each occurrence of the following fields in the bibliographic records: 